\title{
Localização de Peróxido de Hidrogênio Durante a Resposta de Defesa de Tomateiro Contra Stemphylium solani
}

\author{
Jânia L. S. Bentes ${ }^{1 * *}$ \& Kiyoshi Matsuoka ${ }^{2}$ \\ ${ }^{1}$ Faculdade de Ciências Agrárias, Universidade Federal do Amazonas, Av. General Rodrigo Otávio, 3000, CEP \\ 69077-000, Manaus, AM, e-mail: janialilia.bentes@bol.com.br; ${ }^{2}$ Departamento de Fitopatologia, Universidade \\ Federal de Viçosa, CEP 36570-000, Viçosa, MG
}

(Aceito para publicação em 09/03/2005)

Autor para correspondência: Jânia Lília da Silva Bentes

BENTES, J.L.S. \& MATSUOKA, K. Localização de peróxido de hidrogênio durante a resposta de defesa de tomateiro contra Stemphylium solani. Fitopatologia Brasileira 30:643-646. 2005.

\begin{abstract}
RESUMO
Peróxido de hidrogênio foi localizado citoquimicamente em virtude de sua reação com cloreto de cério, evidenciando $\mathrm{H}_{2} \mathrm{O}_{2}$ produzido em tomateiros (Lycopersicon esculentum) resistente e suscetível a Stemphylium solani. Precipitados de peridróxido de cério foram constatados nas células do mesofilo, na parede em contato com as hifas do patógeno. Portanto, não tendo sido observada reação diferencial entre as cultivares quanto ao acúmulo de $\mathrm{H}_{2} \mathrm{O}_{2}$, e, sendo sua presença detectada num dos controles negativos, sugere-se que este composto possivelmente não participe diretamente da resistência manifestada pela c.v. 'Motelle' contra S. solani, no tocante ao fortalecimento da parede celular.

Palavras-chave adicionais: resistência, parede celular, Lycopersicon esculentum, $\mathrm{H}_{2} \mathrm{O}_{2}$.

ABSTRACT

Localization of hydrogen peroxide during defense response of tomato against Stemphylium solani

Two tomato (Lycopersicon esculentum) cultivars were studied due to their reaction with cerium perhydroxide, verifying $\mathrm{H}_{2} \mathrm{O}_{2}$ produced in tomato plants boyh resistant and susceptible to Stemphylium solani. There was an accumulation of cerium perhydroxide on the wall of mesophyll cells in contact with the pathogen hyphae. Different reactions were not found int the two tomato cultivars concerning $\mathrm{H}_{2} \mathrm{O}_{2}$ accumulation. Since cerium perhydroxide was detected on negative control as well, it is suggested that $\mathrm{H}_{2} \mathrm{O}_{2}$ may possibly not participate in the resistance of c.v. 'Motelle' to S. Solani, in terms of cell wall buttressing.
\end{abstract}

Additional keywords: resistance, cell wall, Lycopersicon esculentum, $\mathrm{H}_{2} \mathrm{O}_{2}$.

A mancha-de-estenfílio causada por Stemphylium solani Weber. afeta plantas de tomateiro (Lycopersicon esculentum Mill.) em diferentes estádios de desenvolvimento. Os sintomas são caracterizados por lesões necróticas marromacinzentadas, circundadas por halo amarelo no limbo foliar. O patógeno pode atacar cerca de vinte espécies de solanáceas cultivadas como pimentão (Capsicum annuum L.), jiló (Solanum gilo Raddi) e batatinha (Solanum tuberorum L.) (Mizubuti \& Brommonschenkel, 1996). No entanto, os danos causados dependem da suscetibilidade das cultivares plantadas. O uso de variedades resistentes é a medida de controle mais eficiente contra o fungo (Mizubuti \& Brommonschenkel, 1996).

No início do desenvolvimento de uma doença, as plantas podem induzir uma série de respostas de defesa, incluindo a rápida geração, de "espécies reativas de oxigênio"

\footnotetext{
*Parte de tese de doutorado do primeiro autor. Universidade Federal de Viçosa (2002)

**Bolsista do CNPq
}

(reactive oxygen species, ROS) tais como $\mathrm{O}_{2}^{-}, \mathrm{H}_{2} \mathrm{O}_{2}$ e OH Sabe-se que ROS estão envolvidas na ligação de proteínas estruturais da parede celular, ativação da transcrição de genes, respostas de resistência induzida, deterioração de membranas, indução de morte celular e no desenvolvimento de lesões necróticas (Lamb \& Dixon, 1997; Hückelhoven \& Kogel, 1998; Scandalios, 2002). Diversos estudos têm sido efetuados visando elucidar o papel das espécies reativas de oxigênio nas respostas de defesa das plantas a patógenos. Alguns relatos enfatizam a importância da ligação oxidativa de proteínas e compostos fenólicos na parede celular, mediada pelo $\mathrm{H}_{2} \mathrm{O}_{2}$ (Quiroga et al., 2000; Hilaire et al., 2001; Kozlowska et al. 2001). Outros mecanismos relacionados com o fortalecimento da parede celular, como lignificação (Czaninski et al. 1993; Otte \& Barz, 1996) e formação de papilas (Cadena-Gomez \& Nilcholson, 1987; ThordalChristensen et al., 1997; Hückelhoven et al., 1999), também foram relacionados com a síntese de $\mathrm{H}_{2} \mathrm{O}_{2}$.

A detecção de $\mathrm{H}_{2} \mathrm{O}_{2}$ pode indicar o envolvimento de 
proteínas e outros compostos relacionados com o fortalecimento da parede celular, contribuindo com a resistência da planta ao ataque de patógenos. O estudo do envolvimento deste composto no processo de infecção de Stemphylium solani em tomateiro é de interesse para ajudar a esclarecer quais mecanismos de resistência estão envolvidos neste patossistema. Dessa forma, efetuou-se o presente estudo com o objetivo de localizar peróxido de hidrogênio $\left(\mathrm{H}_{2} \mathrm{O}_{2}\right)$ associado à parede celular de tomateiro, durante a reposta de defesa ao ataque de $S$. solani.

Foram utilizados tomateiros da cultivar Motelle, resistente à mancha de estenfílio, e da cultivar Moneymaker, suscetível. A semeadura foi feita em bandejas de plástico (45 x 30 x 9,5 cm) contendo como substrato solo, areia e esterco de curral, na proporção de 3:1:1, pré-tratado com brometo de metila.

Foi usado um variante esporulante de $S$. solani, S7015, disponível no Departamento de Fitopatologia da Universidade Federal de Viçosa. O fungo foi cultivado em placas de Petri contendo meio de cultura V8 (200 ml de suco V8; $17 \mathrm{~g}$ de ágar; $800 \mathrm{ml}$ de água destilada), por dez dias em temperatura de $25^{\circ} \mathrm{C}$. A suspensão de inóculo foi obtida a partir da adição de água destilada nas placas de Petri contendo a colônia do fungo, a qual foi levemente raspada com um pincel de cerdas macias para a liberação dos conídios. $\mathrm{O}$ líquido foi recolhido em um béquer e a suspensão ajustada para $10^{4}$ conídios/ml. A inoculação foi feita em mudas de tomateiro com cerca de 15 dias de idade, aplicando-se gotas de $30 \mu \mathrm{l}$ de suspensão de conídios, em diferentes locais nas folhas, em seguida as gotas foram recobertas com disco de papel de filtro esterilizado, com cerca de $0,5 \mathrm{~cm}^{2}$, para evitar o escorrimento. Este método foi usado visando facilitar a coleta de amostras, pela localização dos pontos de inoculação e do patógeno nos tecidos do hospedeiro. Após as inoculações, as plantas foram mantidas em câmara de nevoeiro a $25^{\circ} \mathrm{C}$, até o término da coleta das amostras.

Para a localização de peróxido de hidrogênio, foi utilizado o método descrito por Bestwick et al. (1997), que se baseia na reação de $\mathrm{H}_{2} \mathrm{O}_{2}$ com $\mathrm{CeCl}_{3}$, produzindo precipitados de peridróxido de cério, nos sítios de produção ou acúmulo de $\mathrm{H}_{2} \mathrm{O}_{2}$ As amostras foliares foram coletadas $48 \mathrm{~h}$ após a inoculação (h.a.i.), das quais foram retirados fragmentos de 2 $\mathrm{mm}^{2} \mathrm{e}$ incubados durante $1 \mathrm{~h} \mathrm{em} \mathrm{CeCl}_{3}$, a $5 \mathrm{mM}$, preparado em ácido 3-(N-morfolino) propano-sulfônico (MOPS) 50 $\mathrm{mM}, \mathrm{pH}$ 7.2. Em seguida, os tecidos foram fixados durante $1 \mathrm{~h}$ em glutaraldeído a $1,25 \%(\mathrm{v} / \mathrm{v})$ e paraformaldeído a $1,25 \%$ (v/v), preparado em tampão cacodilato de sódio a $0,05 \mathrm{M}$, a pH 7.2. Após a fixação, os tecidos foram lavados duas vezes no tampão de cacodilato de sódio, durante 10 min, e pós-fixados durante $45 \mathrm{~min}$ em $\mathrm{OsO}_{4}$ (tetróxido de ósmio) a 1\%, e novamente lavados, como já descrito. Após este processamento, as amostras foram desidratadas em série alcóolica e incluídas em resina Spurr, como se faz no procedimento convencional para microscopia eletrônica. Os cortes ultrafinos foram confeccionados em ultramicrótomo marca Sorval MT2-B, equipado com navalha de diamante, montados em telinhas de cobre, contrastados durante 30 min com acetato de uranila $2 \%$ em solução aquosa, seguindo-se de citrato de chumbo, durante $15 \mathrm{~min}$. Os cortes foram examinados em microscópio eletrônico de transmissão Zeiss.

Dois tipos de controle foram usados neste estudo. $\mathrm{O}$ primeiro foi amostras não inoculadas das duas cultivares e tratadas com $\mathrm{CeCl}_{3}$. O segundo, amostras inoculadas, das duas cultivares porém não tratadas com $\mathrm{CeCl}_{3}$.

Precipitados de peridróxido de cério foram constatados na parede de células do mesofilo em tecidos infetados da cultivar resistente (Figura 1 A e B) e da cultivar suscetível (Figura $1 \mathrm{Ce}$ D) em contato com hifas do patógeno, indicando a presença no local de $\mathrm{H}_{2} \mathrm{O}_{2}$, independentemente de a planta ser resistente ou suscetível. No primeiro controle, no qual amostras das cultivares resistente e suscetível foram tratadas com $\mathrm{CeCl}_{3}$ mas não foram inoculadas com o patógeno, observou-se a deposição de material eletrondenso na parede celular das cultivares, correspondente a precipitados de peridróxido de cério, indicando a presença de $\mathrm{H}_{2} \mathrm{O}_{2}$. $\mathrm{O}$ conteúdo celular destas amostras apresentou-se preservado, com cloroplastos e mitocôndrias intactos (Figura 2 A e B). No segundo controle, no qual amostras das cultivares

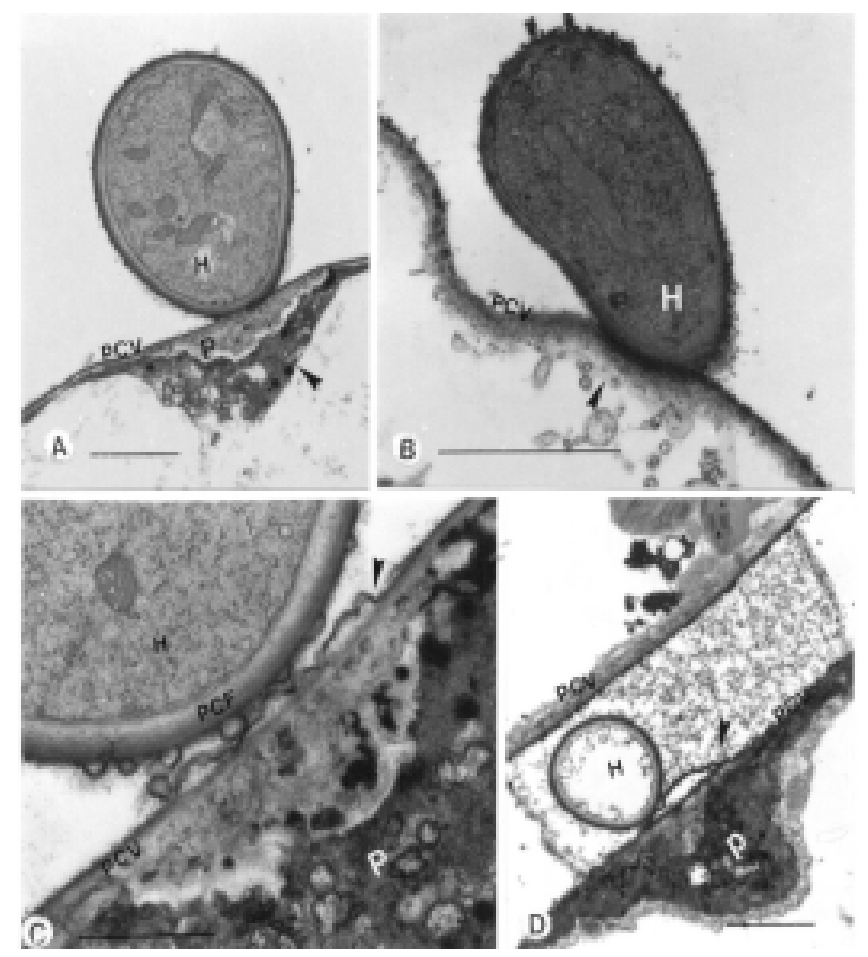

FIG. 1 - Presença de precipitados de peridróxido de cério nas células do mesofilo de tomateiro (Lycopersicon esculentum) resistente e suscetível inoculados com Stemphylium solani. A e B) Deposição de material eletrondenso (setas) junto à parede celular de célula do mesofilo da cultivar resistente. C e D). Acúmulo de precipitados junto à parede celular (setas) em célula do mesofilo da cultivar suscetível em contato com hifas do patógeno. Barra em $\mathrm{A}, \mathrm{C}$ e $\mathrm{D}=2 \mu \mathrm{m} ;$ em $\mathrm{B}=5 \mu \mathrm{m}$. $\mathrm{H}=$ hifa; $\mathrm{P}=$ papila; $\mathrm{PCV}=$ parede celular vegetal. 


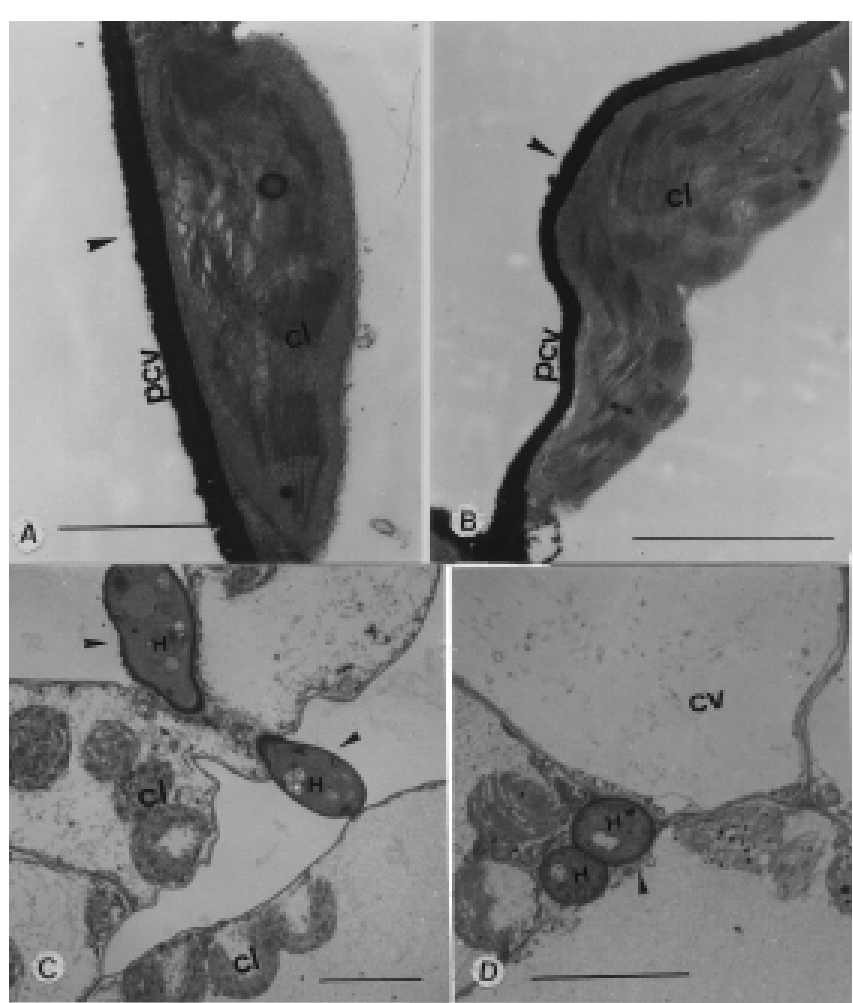

FIG. 2 - Amostras de tecido foliar das cultivares de tomateiro (Lycopersicon esculentum) resistente e suscetível a Stemphylium solani do controle 1 (tratadas com $\mathrm{C}_{\mathrm{e}} \mathrm{Cl}_{3}$ e não inoculadas com o patógeno) e do controle 2 (não tratadas com $\mathrm{C}_{\mathrm{e}} \mathrm{Cl}_{3}$ e inoculadas com o patógeno). A e B) Deposição de material eletrondenso (setas) na parede celular do hospedeiro resistente (A) e suscetível (B) do controle 1, indicando o acúmulo de precipitados de peridróxido de cério. C e D) Hifas intercelulares (setas) em contato com as células do mesofilo da cultivar resistente (C) e suscetível (D) do controle 2, sem acúmulo de precipitados na parede celular vegetal. Barra em $\mathrm{A}=1 \mu \mathrm{m} ; \mathrm{em} \mathrm{B}=2 \mu \mathrm{m} ;$ em $\mathrm{C} \mathrm{e} \mathrm{D}=5 \mu \mathrm{m} \mathrm{cl}=$ cloroplastos; $\mathrm{m}=$ mitocôndrias; $\mathrm{pcv}=$ parede celular vegetal.

resistente e suscetível não foram tratadas com $\mathrm{CeCl}_{3}$ e foram inoculadas com o patógeno, não se constatou material precipitado ou depositado na parede celular do hospedeiro (Figura $2 \mathrm{C}$ e D).

As análises feitas no trabalho presente, visando localizar o acúmulo de peróxido de hidrogênio $\left(\mathrm{H}_{2} \mathrm{O}_{2}\right)$, possivelmente relacionado com o fortalecimento da parede celular do hospedeiro, revelaram a presença de $\mathrm{H}_{2} \mathrm{O}_{2}$ nas duas cultivares em estudo, e no controle negativo em que o $\mathrm{CeCl}_{3}$ foi utilizado. A provável explicação pela qual precipitados de peridróxido de cério apareceram nas amostras do controle tratado com $\mathrm{CeCl}_{3}$ e não inoculado com o fungo, é a presença de $\mathrm{H}_{2} \mathrm{O}_{2}$ constitutivo na célula vegetal. De acordo com Bolwell \& Wojtaszek (1997), a geração de espécies de oxigênio reativo (reactive oxygen species, ROS) é uma característica constitutiva de qualquer célula viva. Em condições normais, as ROS aparecem como resultado de sucessivas reações redutoras de oxigênio molecular. As plantas são capazes de produzir ROS constitutivamente e em quantidades significantes, principalmente $\mathrm{H}_{2} \mathrm{O}_{2}$, e esta produção pode ser regulada pela luz, hormônios ou ferimentos. Segundo Resende et al. (2003), durante o transporte de elétrons nos cloroplastos e mitocôndias, muitos $e^{-}$são perdidos e então captados pelo $\mathrm{O}_{2}$, formando $\mathrm{O}_{2}^{-}$. A dismutação do $\mathrm{O}_{2}^{-}$ catalisada pela SOD (superóxido dismutase), é responsável pelo surgimento da maioria do $\mathrm{H}_{2} \mathrm{O}_{2}$ celular.

Os resultados observados também sugerem que o $\mathrm{H}_{2} \mathrm{O}_{2}$, presente nas células de tomateiro resistente e suscetível, inoculados com o patógeno, pode estar relacionado com respostas intrínsecas de defesa das cultivares estudadas, como a deposição de substâncias na parede celular do hospedeiro, ou a síntese de compostos fenólicos. Hückelhoven et al. (1999) estudaram a presença de $\mathrm{H}_{2} \mathrm{O}_{2}$ em plantas de Hordeum vulgare L. resistentes a Blumeria graminis f.sp. hordei (DC.) Speer e detectaram $\mathrm{H}_{2} \mathrm{O}_{2}$ acumulado em papilas eficientes em conter o patógeno, ao passo que $\mathrm{H}_{2} \mathrm{O}_{2}$ não foi detectado em células onde as papilas se mostraram ineficazes, indicando que o $\mathrm{H}_{2} \mathrm{O}_{2}$ tem papel substancial na resistência, neste patossistema. Cadena-Gomez \& Nicholson (1987) analisaram a atividade de peroxidases associadas com a formação de papilas na epiderme e no mesocótilo de milho inoculado com Helminthosporium maydis Nisikado \& Myiake e Colletotrichum graminicola (Ces.) Wils. e revelaram atividade de peroxidases antes e depois da formação de papilas, como também a presença de fenóis e lignina na parede celular, o que demonstra o envolvimento de $\mathrm{H}_{2} \mathrm{O}_{2}$ nessas respostas.

Sugere-se no presente trabalho que o peróxido de hidrogênio não deva contribuir de forma significativa para a resistência da cultivar Motelle contra S. solani, visto que não se encontrou qualquer reação diferencial entre as cultivares resistente e suscetível, quanto a presença de $\mathrm{H}_{2} \mathrm{O}_{2}$. Entretanto, este estudo foi realizado avaliando-se apenas um período de coleta após a inoculação (48 h), não sendo possível concluir sobre o papel efetivo do $\mathrm{H}_{2} \mathrm{O}_{2}$ na alteração de parede celular do hospedeiro e na manifestação da resistência. É necessária a repetição do experimento, testando-se outros períodos de coleta, visando avaliar a presença deste composto no hospedeiro resistente e suscetível e sua interferência no que diz respeito ao fortalecimento da parede celular.

\section{REFERÊNCIAS BIBLIOGRÁFICAS}

BESTWICK, C.S., BROWN, I.R., BENNETT, M.H.R. \& MANSFIELD, J.W. Localization of hydrogen peroxide accumulation during the hypersensitive reaction of lettuce cells to Pseudomonas syringae p.v. phaseolicola. The Plant Cell 9:209-221. 1997.

BOLWELL, G.P. \& WOJTASZEK, P. Mechanisms for the generation of reactive oxygen species in plant defence- a broad perspective. Physiological and Molecular Plant Pathology 51:347366. 1997.

CADENA-GOMEZ. G. \& NICHOLSON, R.L. Papillae formation and associated peroxidase activity: a non-specific response to attempted fungal penetration of maize. Physiological and Molecular Plant Pathology 31:51-67. 1987. 
CZANINSKI, Y., SACHOT, R.M. \& CATESSON, A.M. Cytochemical localization of hydrogen peroxide in lignifying cell walls. Annals of Botany 72:547-550. 1993.

HILAIRE, E., YOUNG, S.A., WILLARD, L.H., McGEE, J.D., SWEAT, T., CHITTOOR, J.M., GUIKEMA, J.A. \& LEACH, J.E. Vascular defense responses in rice: peroxidase accumulation in xylem parenchyma cells and xylem wall thickening. Molecular Plant Microbe Interactions 14:1411-1419. 2001.

HÜCKELHOVEN, R. \& KOGEL, K.H. Tissue-specific superoxide generation at interaction sites in resistance and susceptible nearisogenic barley lines attacked by powdery mildew fungus (Erysiphe graminis f.sp. hordei). Molecular Plant Microbe Interactions 11:292300. 1998

HÜCKELHOVEN, R., FODOR, J., PREIS, C. \& KOGEL, K. Hypersensitive cell death and papilla formation in barley attacked by the powdery mildew fungus are associated with hydrogen peroxide but not with salicylic acid accumulation. Plant Physiology 119:1252-1260. 1999.

KOZLOWSKA, M., FRYDER, K. \& WOLKO, B. Peroxidase involvement in the defense response of red raspberry to Didymella applanata (Niessl/Sacc). Acta Physiologiae Plantarum 23:303-310. 2001.

LAMB, C. \& DIXON, R.A. The oxidative burst in plant disease resistance. Annual Review of Plant Physiology and Plant Molecular Biology 48:251-275. 1997.

MIZUBUTI, E.S.G \& BROMMONSHENKEL, S.H. Doenças causadas por fungos em tomateiro. Informe Agropecuário 18:7-14. 1996.

OTTE, O. \& BARZ, W. The elicitor induced oxidative burst in cultured chickpea cells drives the rapid insolubilization of two cell wall structural proteins. Planta 200:238-246. 1996.

QUIROGA, M., GUERRERO, C., BOTELLA, M.A., BARCELÓ, A., AMAYA, I., MEDINA, M.I., ALONSO, F.J., de FORCHETTI, S.M., TIGIER, H. \& VALPUESTA, V. A tomato peroxidase involved in the synthesis of lignin and suberin. Plant Physiology 122:11191127. 2000

RESENDE, M.L.V., SALGADO, S.M.L. \& CHAVES, Z.M. Espécies ativas de oxigênio na resposta de defesa de plantas a patógenos. Fitopatologia Brasileira 28:123-130. 2003.

SCANDALIOS, J.G. The rise of ROS. Trends in Biochemical Sciences 27:483-486. 2002.

THORDAL-CHRISTENSEN, H., ZHANG, Z., WEI, Y. \& COLLINGE, D.B. Subcellular localization of $\mathrm{H}_{2} \mathrm{O}_{2}$ in plants. $\mathrm{H}_{2} \mathrm{O}_{2}$ accumulation in papillae and hypersensitive response during the barley-powdery mildew interaction. The Plant Journal 11:11871194. 1997. 